\title{
Submicron Distribution and Association of Copper and Organic Carbon in A Contaminated Soil Using Scanning Transmission X-ray Microspectroscopy
}

\author{
Jianjun Yang ${ }^{1 *}$ and Jian Wang ${ }^{2}$
}

1. Institute of Environmental and Sustainable Development in Agriculture, Chinese Academy of

Agricultural Science; Key Laboratory of Agro-Environment, Ministry of Agriculture, Beijing, China, 100081

2. Canadian Light Source Inc., University of Saskatchewan, Saskatoon, Canada S7N 2V3.

* Corresponding author, yangjianjun@caas.cn

Copper $(\mathrm{Cu})$, as one of the typical heavy metals, is frequently concentrated in soils as a result of mining and smeltering activities ${ }^{[1,2]}$. Since the mobility and bioavailability of $\mathrm{Cu}$ in soils depends greatly on its chemical speciation, molecular-level understanding the distribution and association of $\mathrm{Cu}$ with soil components is important for the prediction of $\mathrm{Cu}$ fate. $\mathrm{Cu}$ was predominantly associated with soil organic carbon (SOC) in contaminated agricultural soils ${ }^{[3,4]}$. Since the heterogeneity of functional $\mathrm{C}$ domains of SOC occurred at the sub-micron spatial scale in soils ${ }^{[5]}$, this probably influence $\mathrm{Cu}$ distribution at the similar spatial scales due to the high affinity of $\mathrm{Cu}$ to functional $\mathrm{C}$-domains of SOC, such as carboxylic-C, aromatic- $\mathrm{C}$ etc ${ }^{[6,7]}$. However, the submicron distribution and association of $\mathrm{Cu}$ with various functional $\mathrm{C}$ domains of the SOC in contaminated soils has been little reported. Scanning transmission X-ray microspectroscopy (STXM) could probe the distribution of various C-domains of $\mathrm{SOC}$ and $\mathrm{Cu}$ at submicron spatial scale ${ }^{[8,9]}$, which facilitates investigating the association of $\mathrm{SOC}$ and $\mathrm{Cu}$ in heterogeneous soils. Therefore, the objectives of this study is to characterize the speciation, distribution and association of $\mathrm{Cu}$ and functional $\mathrm{C}$-domains of SOC in a contaminated agricultural soil clay fraction using multiple synchrotron-based EXAFS and STXM.

In the $\mathrm{Cu}$ K-edge bulk EXAFS spectra (Figure 1), the resolved minor shoulder from 5 to $6 \AA^{-1}$ in the sample spectra was aligned with that of $\mathrm{Cu}$ adsorbed on humic acid, indicating the presence of organic $\mathrm{Cu}$ species. Karlsson et al., also interpreted this shoulder peak as an indicator of organic $\mathrm{Cu}$ species in soils. ${ }^{[10]}$ Furthermore, LCF results exhibited that the three major $\mathrm{Cu}$ species were organic $\mathrm{Cu}, \mathrm{Cu}$ associated with $\mathrm{Fe}$ hydroxide $(\mathrm{Cu}-\mathrm{Geo})$ and $\mathrm{Cu}_{2} \mathrm{O}$. Organic $\mathrm{Cu}$, accounting for $62.4 \%$ of the total $\mathrm{Cu}$ content, was predominant over $\mathrm{Cu}-\mathrm{Geo}(\sim 28 \%)$ and $\mathrm{Cu}_{2} \mathrm{O}(\sim 10 \%)$ in the soil. These results agreed with the dominance of organic $\mathrm{Cu}$ species in the agricultural soils using $\mathrm{Cu}$ K-edge EXAFS analysis ${ }^{[3,4]}$. Furthermore, STXM results exhibited the heterogeneous distribution of $\mathrm{Cu}, \mathrm{C}$ and various $\mathrm{C}$ functional groups including aromatic-C, aliphatic- $\mathrm{C}$ and carboxylic- $\mathrm{C}$ at the submicron scale (Figure 2). The observed overlapping of hot $\mathrm{Cu}$ spots 1 and 2 with $\mathrm{C}$ hot spots 3 and 4 , respectively, indicated the predominant association of $\mathrm{Cu}$ with $\mathrm{SOC}$, in consistent with the bulk $\mathrm{Cu}$ EXAFS analysis (Figure 1) . Further deconvolution of $\mathrm{C}$ speciation revealed $\mathrm{SOC}$ at spots 3 and 4 dominated as aromatic- $\mathrm{C}$ and carboxylic-C rather than aliphatic-C (spot 5). Generally, aromatic-C enriched SOC fraction could originate from undegradable plant residuals and black carbon ${ }^{[11]}$; while aliphatic-C enriched SOM fraction was regarded as microbial origin ${ }^{[5]}$. Therefore, $\mathrm{Cu}$ was preferentially associated with aromatic-C enriched SOM, which agreed with model systems studies ${ }^{[7,12]}$. This study firstly revealed the contrast roles of different $\mathrm{C}$ functional domains of $\mathrm{SOC}$ on $\mathrm{Cu}$ immobilization in the contaminated soil using EXAFS and STXM analysis, which benefit further application of aromatic-enriched biomaterials in the remediation of contaminated soils by $\mathrm{Cu}$ and other heavy metals. 
References:

[1]. J.J. Yang, et al., Environ. Sci. Pollut. Res. 21(2013) 2943

[2]. J.J. Yang, et al., Water Air Soil Pollut. 205(2010) 333

[3]. D.G. Strawn et al., Environ. Pollut. 157(2009) 2813

[4]. D.G. Strawn et al., Environ. Sci. Technol. 42(2008) 37

[5]. J. Lehmann, et al., Nature Geosci. 1(2008) 238

[6]. T. Karlsson, et al., Environ. Sci. Technol. 40(2006) 2623

[7]. J. Ippolito, et al., J. Environ. Qual. 41(2012) 1150

[8]. J.J. Yang, et al., Anal. Chem. 83(2011) 7856

[9]. J. Liu, et al., Acta Chimica Sinica. 75(2017) 617

[10]. T. Karlsson, et al., Environ. Sci.Technol. 42(2008)5449

[11]. A.R. Jacobson, et al. Environ. Sci.Technol.. 41(2007) 6343

[12]. J. Jiang et al., J. Hazard. Mater. 229(2012)145

[13]. Thanks for the final support from NNSF of China (U1632134) and Key Laboratory of Agro-Environment, Ministry of Agriculture (Y2017PT53).

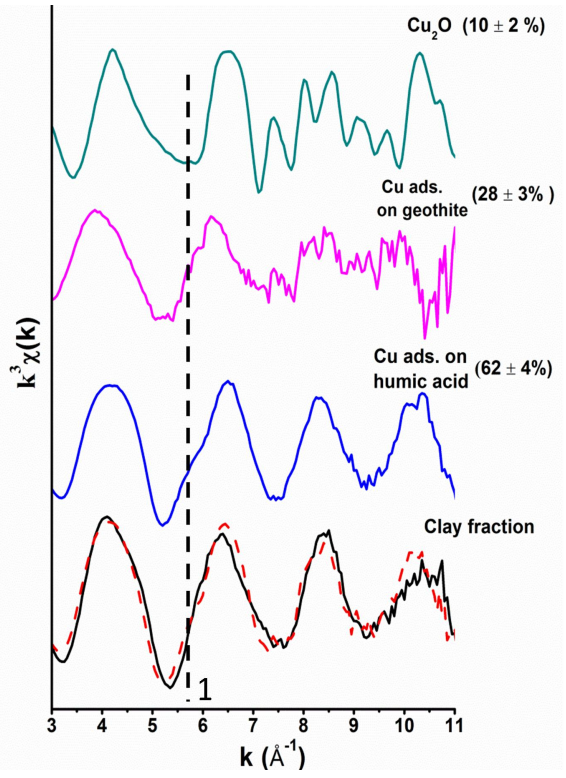

Figure 1. Characterization and quantification of $\mathrm{Cu}$ speciation in the clay fraction of the contaminated soil using fingerprint and linear combination fitting analysis. Peak of interested was labeled as 1 , the dashed red line is the fitting spectrum and the black solid line is experimental spectrum; the $\mathrm{R}$ factor and reduced chi-square for the fitting were 0.1073 and 0.6093 , respectively.
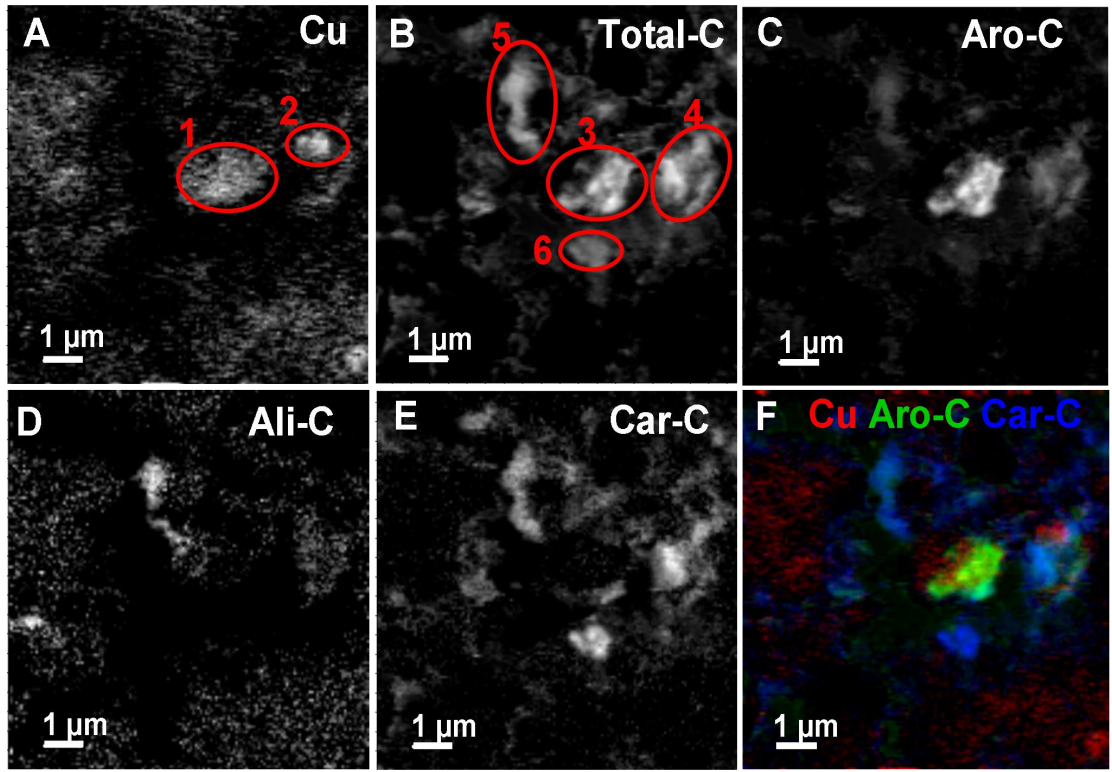

Figure 2 Submicro-scale distribution of $\mathrm{Cu}$ and different organic $\mathrm{C}$ in the investigated soil clay fraction determined by STXM. A, Total Cu (subtraction of energy region at $926.3-$ $927.3 \mathrm{eV}$ from $931-932 \mathrm{eV}$ ). B, Total carbon (subtraction of energy region at $280-282 \mathrm{eV}$ from $290-292 \mathrm{eV})$. C Aromatic-C (Aro-C, subtraction of energy region at $280-282$ eV from $284.5-286 \mathrm{eV}$ ). D, Aliphatic-C (Ali-C, subtraction of energy region at $284.5-286 \mathrm{eV}$ from $287.3-287.8 \mathrm{eV})$. E, Carboxylic-C (Car-C, subtraction of energy region at $284.5-$ $286 \mathrm{eV}$ from $288-289 \mathrm{eV}$ ). F, Overlapping of $\mathrm{Cu}$, Aro-C and Car- $\mathrm{C}$ in the investigated soil clay fraction assembles. Spots of interested are labeled as 1 to 6 . 